\title{
Post-print version
}

CROSS, R., 2015. 'Implementing a Resource List Management System in an academic library'. The Electronic Library.

The published version, can be cited as:

CROSS, R., 2015. 'Implementing a Resource List Management System in an academic library'. The Electronic Library, 33 (2), pp.210-223.

http://dx.doi.org/10.1108/EL-05-2013-0088 


\begin{abstract}
Purpose

- The purpose of this paper is to review the key components of the introduction of a new resource list management system (RLMS) at Nottingham Trent University (NTU) using the Aspire application from Talis Education. It explains the key service goals; the implementation milestones; the main technical challenges which needed to be addressed; and the dynamic relationship between the rollout of the RLMS and existing selection, acquisition and resource delivery processes.
\end{abstract}

\title{
Design/methodology/approach
}

- This evidence in this paper is drawn from the experiences of the NTU RLMS project group, which involved colleagues from Libraries and Learning Resources, Information Systems and the Virtual Learning Environment (VLE) teams at the university. It draws on both qualitative evaluations and quantitative assessments of adoption and use by academics, students and library staff; and the internal mechanisms of project review.

\section{Findings}

- This paper concludes that the successful technical implementation of a cloudbased mission-critical service for academics and students depends on a successful collaboration between library, VLE and technical teams; and reaffirms that a hosted RLMS service still requires the deployment of local technical expertise. It is essential (although not always straightforward) to try to anticipate the impact that the introduction of a new RLMS will have on existing processes (inside the library and without). Ultimately, however, the successful implementation of an RLMS is dependent on securing its adoption by both academics and students; not least by ensuring that the application meets their needs. Although it is not a technical prerequisite, the prospect of a successful implementation of an RLMS is greatly improved when working with the grain of a supportive institutional policy environment.

\section{Originality/value}

- Interest in "next-generation" resource list systems which can address the needs of students, academics and library services is likely to increase sharply in the next few years, as library services seek to align both resource spend and resource discovery more closely than ever with the student experience around "directed reading". The experiences of an "early adopter" implementer of an RLMS highlight some of the key prerequisites and significant operational decisions, and provide a number of insights for those about to embark on a similar implementation process.

\section{Keywords:}

Library services, Library systems, Online learning, Reading lists, Resource lists 


\section{Implementing a Resource List Management System in an academic library}

Richard Cross

Interest in the role that online 'resource lists' - collections of materials selected by academics; supported by academic library services; and delivered to students - can play in underpinning 'directed learning' has been increasing sharply within the higher education sector in the last few years (Atkinson, 2010; Chad, 2010; Chad 2012; Clarke, 2009; Telstar, 2010).

Encouraged by technological and pedagogical developments, attention which earlier focused on the need to support academic 'reading lists', implicitly recognised as collations of print-bound, book-based materials (Sherwood, Lovecy, 1997; Stopforth, 1994) is refocusing on the need to manage multi-format, blended collections of integrated learning materials: the 'resource list' (Chelin, McEachran, 2005; McDowell, 2002; Rieger, Horne, Revels, 2004; Secker, 2005). Driven by the changing teaching practices of academics and the expansion in the range of teaching materials managed by academics libraries, this shift in emphasis has begun to be recognised by software providers developing next generation resource lists solutions (Boyle, 2004; Martin, Stokes, 2006; Stainthorp, 2011).

In recent years, many academics have revised their approach to the dissemination and discovery of reading materials; moving away from a simple print format list, bundled into a module pack or handed out in the tutorial setting. Interest in the provision of online resource lists has evolved in parallel with the growth in adoption of virtual learning portals (VLPs) and, subsequently, of virtual leaning environments (VLEs). Yet despite growing academic interest, most commercial VLP or VLE providers have incorporated reading or resource list functionality into their offerings in only the most rudimentary of ways; usually providing a simple authoring widget, combined with some external link-to functionality. In many universities, 'reading list' widgets in the VLE were often managed in ways which put them beyond the reach of the local library service. Some institutions have developed bespoke in-house solutions for 'reading list' integration, often opting to pull bibliographic data from more permeable external data sources (unconnected to the institution's own collections) rather than attempting to extract data from the sometimes surprisingly uncooperative local 
library management systems (LMSs). A corollary of this is that several of the leading LMS providers have experimented with providing 'reading list' functionality in the setting of the library's online public access catalogue (OPAC). These solutions have tended to operate independently of the local VLE, been functionality limited and often locked-in to the library's existing inventory of title level book and journal catalogue records.

As a consequence of these developments, online resource list applications have, until recently, largely been developed as an outsourced plug-in, sandwiched between the virtual learning environment and the library catalogue, focusing primarily on the business of presenting links to students.

A shortcoming which all of these approaches to reading list management share is that they approach the question of provision in a partial, fractured way (from a particular use perspective) and, in the process, fail to meet fully with the different requirements of the three cohorts who need to engage with the service: lecturers, students and librarians.

With attention both from commercial software providers and the open source community, engineers and designers have (with varying degrees of success) recognised the aspiration for seamless integration between the resource list solution, the virtual learning space and the resource discovery and delivery environments.

Through the implementation of a resource list management system based on the Talis Aspire software, Libraries and Learning Resources at Nottingham Trent University (NTU) was able to successfully introduce a new online service which: integrated with the VLE; connected to the key library resource discovery solutions; and plugged-in to (updated and redesigned) library processing workflows. Impressive levels of take-up by academics, and positive feedback from students during the first full year of operation provided clear evidence of early success for the new RLMS, but also highlighted key areas requiring enhancement by the software providers and further areas of work on promotion and service support required from the library. Following a range of further developments in these areas, resource list adoption had reached $100 \%$ within two years: with every active taught module offering its students a resource list, owned and managed by the course's teaching staff. 


\section{The resource list service problem}

Prior to the resource list project, feedback from students at NTU on the issue of directed reading consistently indicated that inadequate 'reading list' provision was a significant, recurrent irritant for students. Complaints focused on two key issues: firstly, that students were unable to locate, through the services of the library, the materials which their lecturers had asked them to consult (the 'I can't find the things on my list' problem). Secondly, there was frustration from some students that some lecturers did not provide them with lists of resources to support a particular module or course's learning objectives (the 'I can't find a list of things' problem) (Cross, 2012).

As well as the question of inconsistent coverage, the reading list environment was also seen as confused and difficult to navigate: some lists were included in module guides; other lists were loaded into the VLE filestore; others were handed out in print format during lectures or seminar sessions (sometimes seminar lists were being made available to students on a just-in-time basis throughout the course). Taken together, LLR calculated that it was actively managing acquisition for around $20 \%$ of potentially available lists (based on the number of taught courses for which resource lists ought to have been made available to students). It was recognised across the university that the entire resource list environment was in need of an urgent and comprehensive overhaul. Libraries and Learning Resources was tasked with the provisioning of a new endto-end resource list solution, which would go live ahead of the 2010-11 academic session.

In planning the introduction of a new service, three recurring themes remained pre-eminent (Cross, 2011a). Firstly, the library service acknowledged that any new software solution would provide the engine and enabler for the service, but that the successful delivery of a comprehensive new resource list service would require institutional buy-in and co-ordinated university-wide effort. The software would be a prerequisite, but not in itself a guarantor, of success. Secondly, that a new resource list system was certain to be an agent of change, triggering the review of existing practice and culture within both the library service and the wider teaching academy. In the desire to overhaul existing inadequate provision, adoption would, of necessity, be disruptive in the immediate term. Thirdly, that however much the new system led to the realignment and 
improvement of university processes, the key metrics by which the success of the resource list environment would be judged would be (a) improved student satisfaction with the provision of 'direct reading'; and (b) evidence of increased student engagement with reading list resources made available by the library service.

\section{The resource list software environment}

Compared to the market for library management systems, discovery portals, link resolvers, and even the more recent electronic resource management (ERM) applications, the number of companies vending resource and reading list software has remained relatively small. LearnBuild, a Liverpool-based company which offered a hosted resource list service had established a foothold market share in the early 2000s, supporting a small number of university customers, but has since ceased trading. The company Talis had secured a far more extensive customer base for their 'reading list' solution Talis List, which had, over the course of 5-6 years, been adopted by a sizeable number of UK HE institutions (Morgan, 2010). In the absence of a mature commercial market, several UK universities have developed in-house reading list systems, taking on independent responsibility for development, maintenance and support work (including the universities of Aberystwyth, Huddersfield, Leeds, York, and Worcester).$^{1}$

Open source reading list solutions to emerge in the UK include LORLS (Loughborough Online Reading List System), developed over a ten year period at the University of Loughborough (Brewerton, Knight, 2003; Knight, Cooper, Brewerton, 2012), and in service at a number of universities. The 2010 TelStar project at the Open University, which developed a new resource list system for the Moodle open source VLE, utilising APIs from the RefWorks reference management application, has been adopted by Southampton Solent University, amongst others (Telstar, 2010; Young, 2012). A JISC-funded project at the University of Kent which pump-primed the development of a new open source resource list application named List8D (Pitkin, 2011) concluded with the completion of a functional first version in 2009-10, but work on the advanced prototype has since been discontinued (Sotillo, 2012). 
Between 2010 and 2012 several new commercial resource list (or reading list) solutions came on to the market. First amongst these was Talis Aspire (initially launched by Talis Information Limited, and now sold by Talis Education a division of the Talis Group). Over that three year period, Talis Aspire has been adopted by more than 50 UK universities to become the clear market leader. In July 2012, PTFS Europe launched the Rebus:list reading list application, which had been adopted by three UK universities by the end of the year. New start-up UNILIBRI, established in 2010 brought its reading list software to market in autumn 2012, and was (in September 2013) actively seeking its first customers. Another new start-up in this area, established in November 2011 and launched in 2012, is Student Reading Lists, an online service which links primarily book-based content selected by academics to online retailers for student purchase, through affiliate relationships independent of the library or university. ${ }^{2}$

In 2009-10, although the market was less mature, the high level specification requirements for a new resource list management system were already clear. Driven by clearly articulated service need, a tendering exercise at NTU, undertake in 2010, concluded with the decision that LLR would become an 'early adopter' for Talis Aspire (the new resource list solution from Talis) joining the two other existing customers. Becoming one of three early adopters of the solution enabled LLR to influence the further development of the product. At the same time LLR acknowledged that not all elements of the functionality deemed in the specification as 'highly desirable' would be incorporated in the product at the time the service launched locally.

\section{Talis Aspire}

Talis Aspire is made available exclusively through Software as a Service (SaaS) model; interconnected with local-hosted (or other remote) applications as required, but provided through a shared tenancy, cloud-based infrastructure. Rather than being built through a traditional relational database environment, Talis Aspire is a based on the architecture of 'linked data'; and is closely aligned to the company's wider strategic objectives in relation to both open data modelling and the semantic web (Clarke, 2009). Authentication and authorisation is required for all aspects of the creation, editing, publishing (and ultimately withdrawal and 
archiving) of lists; but the contents of lists can (as a default) be openly discovered through both persistent deep-links and the application's own tenancy level search engine.

Academics responsible for the management of a resource list author and publish that list through the use of an online editing screen; the main tool of which is provided through a drag-and-drop interface. Items previously 'bookmarked' by the academic (such as books, journal articles, videos or web sites) can be added to a list; grouped in named sections (which can be nested, to provide sub-sections within sections); annotated with supporting notes or guidance; and given a relative importance rating (from an agreed taxonomy). Lists can be saved as a work-in-progress, not yet visible to the student; or published, so that their contents are immediately discoverable. Once a list has been published, the academic can then begin work on a new draft version of the list (unseen by the student, and distinct from the published one). The academic can then choose when to publish that revised draft list, making it visible to students and replacing the earlier live version.

Prospective students Current students Business Research Staff Alumni

NOTTINGHAM

TRENT UNIVERSITY

\begin{tabular}{|l|l|l|l|l|l|l|} 
Home & My Lists & My Bookmarks & Reviews & Feedback & Admin & Reports
\end{tabular}

\section{IR Link checking 01 (201213)}

Richard Cross

a librarian

Edit | Copy | Recent changes | Export to CSV | Export citations | Invite List Publishers | Review | Request review | Review history | Archive | Set Licence | A Description: A 'link checking' demonstration list for Information Resources colleagues in LLR

Created: 8 months ago

Last updated: 7 months ago

Table of contents [show]

12 items

Haunted by the Spirit of '77: Punk Studies and the Persistence of Politics., 2006 Article

DOI - Bookmark recognizer platforms ( 5 items)

The following platforms are configured for automatic DOI extract at the article level

Highwire (Oxford University Press) (1 item)

Anticoagulation for atrial fibrillation: should warfarin be temporarily stopped or continued after acute cardioembolic stroke? - P. D. Mudd, M. A. James, 2010 . Article

[[ Figure 1: The list level view in Talis Aspire, showing nested sections and the extendable Table of Contents link]] 
For items held in the library inventory, Talis Aspire will display real-time item availability in the full view of each individual item (once this has been configured for a customer's LMS), and a deep-link to that item record in the library discovery environment online materials (whether electronic resource records bookmarked from the library discovery system; or online materials bookmarked direct from the web) each record in Talis Aspire will include a clickable link to the resource. Talis continue to explore the potential for 'in-lining' material directly within the Talis Aspire interface, rather than linking to it remotely. To demonstrate the potential of this functionality, YouTube video material bookmarked by academics are presented to the student directly within Talis Aspire (using automated extraction of the 'embed object' code provided by YouTube).

\section{This item appears on..}

List: Stages - Demonstration - 01

Next item: Tourism distribution channels: practices, issu...

Previous item: Religious identities in Henry VIII's England

\section{Library availability}

\begin{tabular}{lll} 
Collection & Shelf Mark & Availability \\
\hline Boots Library & 658.8 LAN & 5 of 6 copies available \\
Brackenhurst Library & 658.8 LAN & $\begin{array}{l}1 \text { copy on-loan, due } \\
\text { back } 31 / 5 / 2013\end{array}$
\end{tabular}

View in library catalogue

Search the library catalogue for other formats/editions

[[ Figure 2: A real-time item availability display for an item of library stock in Talis Aspire]]

Academics are able to gather and manage 'bookmarks' for their resource lists in a number of different ways. An ISBN, DOI (Digital Object Identifier) or LCN (Local Control Number from the LMS) can be added to a look-up screen within Talis Aspire and the required metadata (such as author, title, year of publication) returned through an automated look-up. A JavaScript-based Bookmarklet (for Internet Explorer, Firefox and Safari) can be added by academics to their preferred browser; which provides a one-click extraction of metadata from the library 
catalogue or search engine (once configured), and from a growing number of fulltext journal provider platforms (such as Elsevier Science Direct, IngentaConnect, HighWire and others). ${ }^{3}$ Talis Aspire is now also able to leverage inbound OpenURL links; extracting the metadata in Context Objects submitted by third-party link resolvers.

In those cases where bookmarked metadata contain an ISBN, Talis Aspire privileges existing library catalogue records and holdings data over other sources. If an ISBN is retrieved, for example, from the Amazon platform, Talis Aspire will first check the local library inventory. If it finds a match, metadata (including the LCN) to populate the bookmark be retrieved from the catalogue. If no match is found, Talis Aspire will query the OpenLibrary catalogue record set for a match and retrieve the best available metadata from that source.

\section{Add this item to your bookmarks}

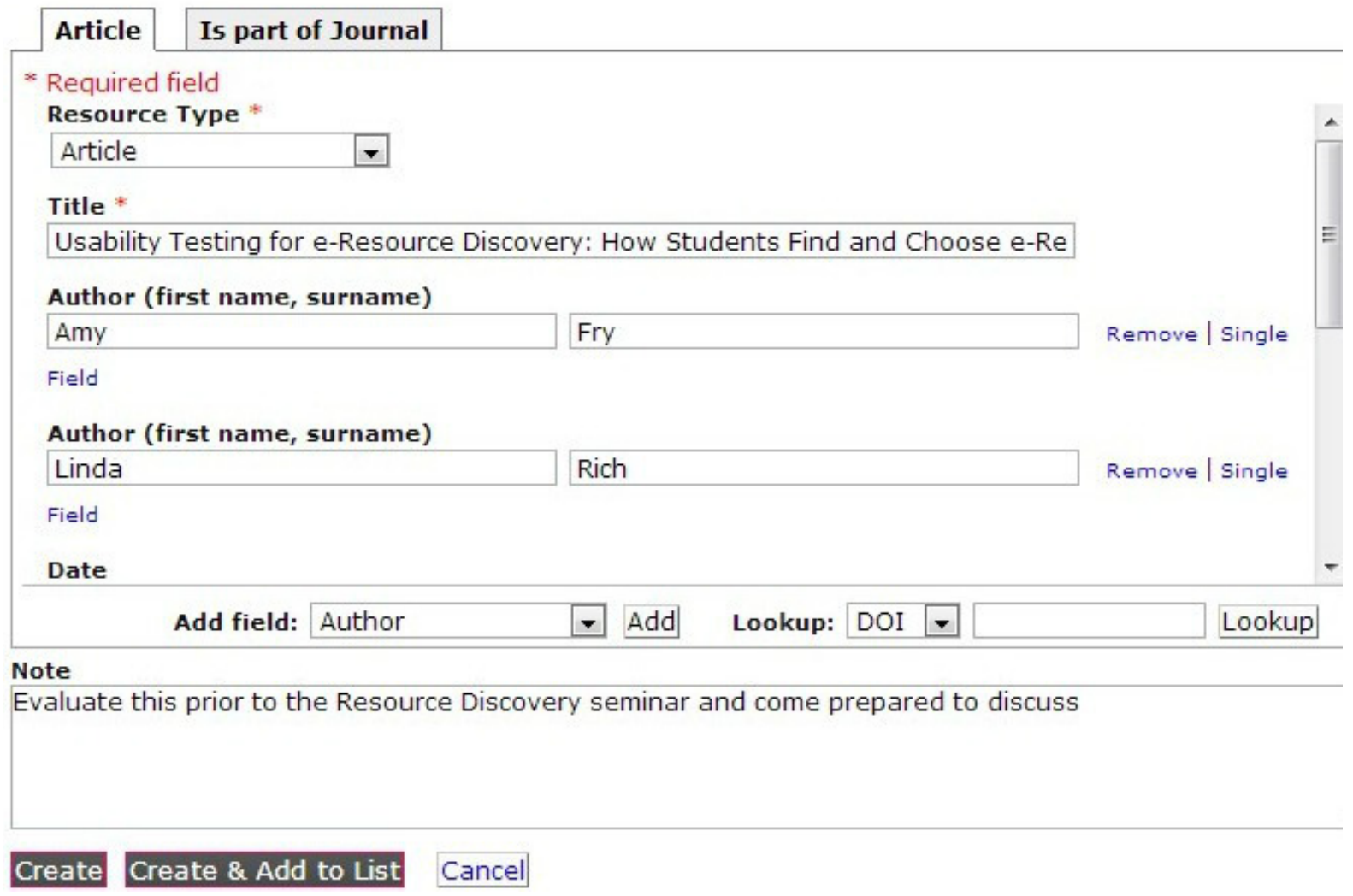

[[ Figure 3: The Preview screen which allows the user to review and annotate an item's metadata before adding details to their Bookmark collection in Talis Aspire]] 
Once lists have been published, students can access them either through subject keyword or identifier (such as course code) searches within Talis Aspire, or by deep-links from within the corresponding space within the VLE. Talis Aspire provides a linking API which enables information about lists associated with a module (name, link, item count, last-updated data, and year [or other temporal identifier - such as semester]) to be retrieved in a number of different formats through a simple web call. A number of different VLE plug-ins for Talis Aspire have been developed using this API, including ones from Moodle, Blackboard and (at NTU) Desire2Learn. Usage data evidence from different Talis Aspire customers indicates that, where deep-linking from the VLE is provided, it becomes the overwhelmingly most popular route for student access of resource lists. At NTU, more than $95 \%$ of access requests to resource list content originate as deep-link requests from within the VLE.

In addition to (academic) authorship and (student) discovery of resource lists, the third component of the list workflow is provided through the process of 'library review'. When an academic has completed a round of work on a list, they are able to submit that list for the attention of the library. After selecting the 'submit for library review' option, the academic is able to add optional additional information; such as the number of students enrolled on the course the list is supporting, and any supporting information (in free-text). Library staff can then review all of the items on a list (including any item-level library notes from the academic) along with the relative priority status assigned to each item.

Talis Aspire does not attempt to replicate any of the ordering, tracking, claiming, invoicing or payment activities of the institution's LMS, but does enable the library service to track acquisition events at the item level. As part of the workflow, a free-text notes field (automatically signed and dated) can be serially updated to track the intra-library dialogue accompanying the completion of different acquisitions processes. A customisable drop-down can be used to record final outcomes at the item level (such as 'Electronic purchase approved', 'Existing stock sufficient' or 'Additional print copies ordered'). In addition, the more recent rollout of the concept of 'stages' in Talis Aspire introduces support for list-level workflows. When activated, 'stages' enables libraries to set customisable labels (such as team or task names) for each component of the local list review process, and to assign lists for the attention of individual staff members. A resource list 
under review can then be moved through each 'stage' of activity until completion; improving the library's ability to track and monitor throughput.

Through the inclusion of this library-workflow-focused component, Talis Aspire aims to complete the software's support for the three different cohorts of resource list users, and offer a comprehensive single-application solution to the challenges of resource list authoring; the delivery of online lists to students; and library-mediated provision and discovery of resource list materials.

\section{NOTTINGHAM \\ TRENT UNIVERSITY \\ \begin{tabular}{l|l|l|l|l|l|l} 
Home & My Lists & My Bookmarks & Reviews & Feedback & Admin & Reports
\end{tabular}}

\section{Essentials of marketing: text and cases}

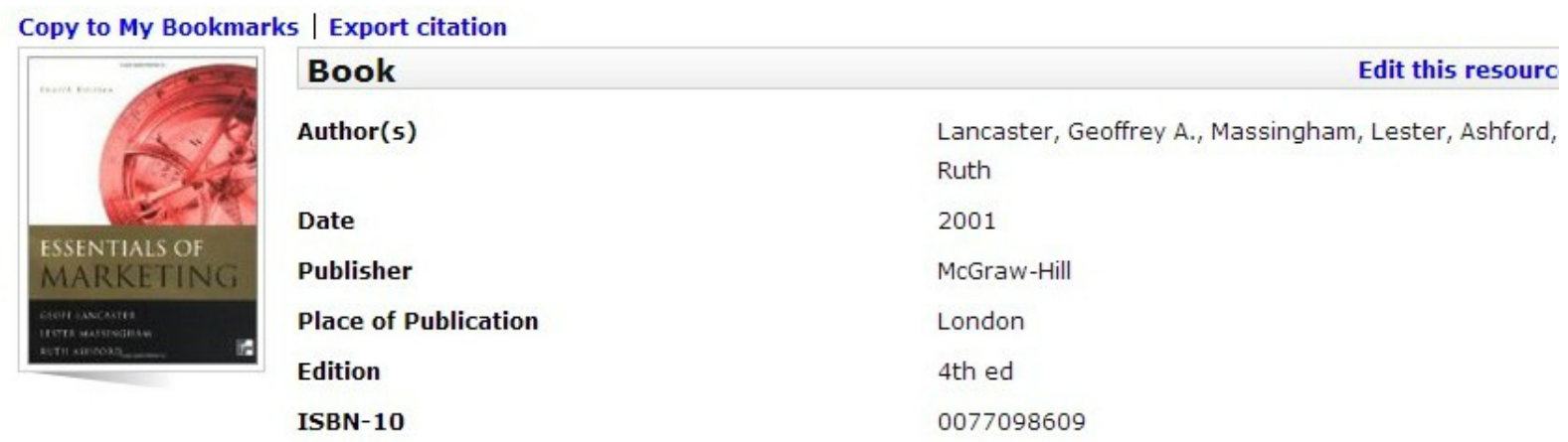

[[ Figure 4: A detailed display for an individual resource list item in Talis Aspire]]

\section{Implementing Talis Aspire}

The successful implementation of the new RLMS at Nottingham Trent University was premised on effective co-operation and collaboration between LLR; the team supporting the virtual learning environment; specialist colleagues in the Information Systems (IS) team; and academic managers and individual academic enthusiasts within the university's schools.

An even more significant pre-requisite was the university's adoption of a conducive policy environment. New guidance on taught course provision required that a minimum online presence be offered for every course, at all levels. The inclusion of a resource list was a specified requirement in this new minimum standard. This was communicated to academics through all appropriate course 
and teaching committees with the strong backing of the senior university managers. This encouraged increased levels of academic engagement with the new resource list application; and, crucially, reinforced the understanding across the institution that the new RLMS was a university-wide initiative (being managed and promoted by the library) rather than a project being championed by the library of its own volition.

At Nottingham Trent University the decision was taken to launch a centrally managed service in which academics own and update their own lists and in which the library makes specific commitments (in terms of acquiring, licensing and provisioning materials) based on the relative importance value assigned to individual list items. This effectively enabled the library service to promote its resource list 'contract' with academics and lecturers; making explicit the resourcing commitments that the library would deliver on for those academics using the system to deliver directed reading materials to their students.

\section{The nature of implementation}

As a cloud-based SAAS solution, the implementation of the Talis Aspire 'tenancy' is handled by the Talis implementation team, with minimal requirement for local input from the institution's systems or technical staff. Library or VLE teams may be involved in preparing course hierarchy data for loading into the tenancy (to reflect a current snapshot of the learning and teaching environment within Talis Aspire) and with the preparation of legacy reading list data (which can also be bulk loaded into Talis Aspire, to part-populate the tenancy with existing reading list content, if so required). The tenancy can also be styled (within functional constraints) to reflect the institutional brand.

Several key integrations with third-party systems are also delivered by Talis as part of implementation. Institutions using an OpenURL link resolver can have a text or button based OpenURL link appear in the full item display of resource list materials to provide 'appropriate copy' linking. The integration of Talis Aspire with the local Library Management System comprises several separate strands (each of which is ultimately dependent on the permeability of the local LMS). Talis will configure the library discovery system (OPAC or next generation discovery portal) as a 'bookmarking' source. 
A successful LMS integration also means that real-time availability information for physical items of library stock will display in the item view (using, for example, z3950 requests to the LMS). The extraction of bibliographic data and the availability display are leveraged using the Local Control Number of System Number of the LMS. In the Acquisitions screens of Talis Aspire, the inclusion of item LCN/SN values in library item records supports one-click review of existing stock levels.

Library discovery integration with Talis Aspire (pulling data from the LMS into the resource list system) is implemented directly by Talis, while VLE integration (deep-linking from the VLE to resource lists in Talis Aspire) involves more hands-on work by the local library or VLE teams. The list-linking API in Talis Aspire enables resource lists widgets or web parts to be built for the local VLE, providing real-time calls to Talis Aspire on list availability. The list-linking API offers list-level deep-linking (to year or semester specific versions of lists, if required); a count of the number of items on a list; and a last-updated date. Talis have made available pre-configured widgets for the Moodle and Blackboard systems, while customers of other VLE systems have developed their own bespoke solutions based on Talis's scripts, which may be shared with other customers.

\section{Engagement and take-up}

The policy environment which encouraged lecturers to adopt resource lists was further reinforced by the 'contract with academics' that the library was able to publicise. "Work with the RLMS and the library will be able to support and resource your lists" became the mantra. Engagement with the RLMS would enable the library to effectively resource those lists by ensuring that the library held sufficient copies of physical material alongside validated and persistent access to electronic and online items: supporting teaching needs and meeting student expectations of directed reading provision.

Training for academics was championed by the Academic Liaison Team who arranged one-to-one and group training sessions for lecturers (a total of 368 individual and 53 group sessions in the first academic year); a process reinforced 
by the identification of individuals and groups of academic 'champions' within schools and departments who formed a cohort of enthusiastic early adopters.

The need to prepare back-of-house library services to support the new resource list environment was the catalyst for a wholesale review of the existing acquisition and collection development methodology. To expedite acquisitions decisions and reduce the degree of item-by-item review a formula was agreed which leveraged the importance of the item against the number of students on the module and (in the case of physical items of stock) the number of copies already held by the library. With the default being to purchase multi-user electronic books wherever possible, RLMS processing was allied to the epreference model already informing the day-to-day practice of the acquisitions team, and the wider collection development policy.

Lists under review needed to be worked on by several different teams within the library. Initially, lists are sanity-checked by members of the Academic Liaison Team. For all purchasable items on a list, liaison librarians either confirm that materials can be acquired to the agreed formula (if existing stock is insufficient) or indicate where exceptions to the standard rule are necessary. The annotated lists are then passed to the acquisitions team who action the necessary purchases and update items on the resource list as required. Next the list is passed to the Resource Discovery and Innovation team, who update the metadata for those electronic records for which only basic details have been auto-extracted and validate the URLs (to ensure access to subscription content is available on and off campus and that e-links are persistent). If required, the list is then passed to the Document Supply and Delivery team to carry out any digitisation tasks required (such as securing the licensed and copyright cleared scanning of book chapters or journal articles).

\section{Student and academic experience}

As part of the implementation process, student focus groups were convened by the Academic Liaison Team, to confirm the points of weakness (from the student perspective) of the then-current resource list system (the 'what's wrong with what we've got?' question); assess student expectation in the area of resource list provision (the 'what do you think you ought to have?' question); and to review, 
through a series of simple practical tests, student perception of the utility of the library's new resource list service (the 'is this closer to what you need?' question). Overall, the focus groups generated consistently positive feedback; with students especially favourable about the discovery aspects of the new system (electronic deep-linking and real-time library availability), and strongly supportive of the university's plan to ensure $100 \%$ of taught courses provided its students with a current, and appropriately populated, resource list. The focus groups provided rich anecdotal evidence of student backing for the goals of the RLMS project, which was reinforced by a local survey in spring 2011 (which attracted more than 1000 student respondents) that confirmed very high levels of interest in improved resource list provision. Both qualitative and quantitative student review of the service, through a combination of national student and local institutional surveys, continues to be appraised and analysed following the launch of the live service.

Liaison librarians also worked closely with teaching academics across all schools within the university. In addition to providing familiarisation training for all lecturers, in-depth appraisal of selected academics' engagement with the new RLMS was also jointly undertaken by NTU and Talis; which focused in particular on the issues of usability, potential barriers to adoption, and the role of system generated feedback.

On this latter issue, the subsequent introduction of on-demand list usage data in Talis Aspire (through a new Dashboard facility) has proved to be an important stimulus for academic review of the structure, length and resource format balance of individual resource lists. The Dashboard feature provides up-todate metrics on student access to the resource on a resource list, identifying the most popular materials and flagging up underused or overlooked items on a list.

\section{Challenges of implementation}

As well as the advantages which accrued to being an early adopter, it was a challenge that some of the features necessary to LLR's start of term launch were still in active development during the course of our implementation process.

The openness of the Talis Aspire system brought many advantages with it (not least the absence of a student sign-in challenge simply to consult a list) but for some academics more reluctant to embrace the new application there were 
concerns about the open visibility of what some considered their intellectual property. Although the empowerment of academics to create, update and maintain their own lists was an equally attractive proposition for many, time-poor academics were sometimes reluctant to set aside time to familiarise themselves with the application and to create lists.

Prior to the adoption of Talis Aspire, links to electronic resources in the library environment were mediated by the library (through connections provided in the catalogue, link resolver and other services). With academics now able to add direct links to online resources to their resource lists, a new task for the library arose: to ensure that that those links were resilient and dependable. For subscription content, the challenges of persistent deep-linking were significant. In addition, the range of free-to-access internet material which academics selected was unexpectedly diverse, and training and local documentation had to be developed to support academics and library staff involved in the validation of links.

For those online resources compatible with the bookmark plugin, the automatic extraction of metadata and links was a relatively simple business. However, for the large amount of online material not yet bookmark compatible, only basic information (URL, and page Title tag data) is extracted, meaning that a significant amount of sustained intervention is required to manually add the missing metadata and to create sustainable authentication-aware links.

The resynchronisation of our course environment with that provided in the RLMS has continued to require manual staff intervention (based on change reports generated from the VLE). The introduction of 'time periods' in Talis Aspire (academic year, part-year, semester, and so on) has enabled the support for the creation of 'temporally associated' lists (e.g. a 2013-14 version of a list, distinct from its 2012-13 predecessor). This has enabled the Tenancy-wide 'rollover' of lists from one academic session to another; something LLR successfully achieved for the first time in the spring of 2011. Later that year, this process was mainstreamed within the application's administrator interface - meaning that Talis Aspire sites can schedule the rollover process to suit local timetabling requirements.

\section{Implementing an RLMS - a review}


The implementation of RLMS at Nottingham Trent Universities had enabled us to begin to successfully address a key irritant reported by students; to empower academics and to encourage them to work more closely with the library in support of resource lists; and at the same time has required LLR to reassess its acquisitions and library review processes in order to support what has been a major reorientation of its workflow priorities, to ensure the timely satisfaction of resource list need.

Following a concerted adoption drive in the spring and summer of 2012, the percentage of active taught courses for which a current resource was available reached $100 \%$, prior to the commencement of the main autumn term. Comprehensive resource list provision for students across all disciplines in the university was an explicit success measure for the project. Given the increasingly modularised and year-round nature of course delivery, mainaining complete resource list adoption across all taught areas will require continuing collaborative effort.

With that key quantitative target reached, greater efforts are now been focused on supporting academics in enshrining 'best practice': raising the qualitative standard of all lists, and improving the student experience, through the effective exploitation of Talis Aspire's more advanced authoring features. Renewed attention is also being directed towards shortening still further the time the library takes to acquire, activate and make discoverable new resource list content.

The successful implementation of a resource list solution in a higher education setting certainly requires leading edge resource list software, but success is not ultimately premised on technology. That software is an enabler (and can also be a catalyst and driver) but it is the willingness of the academic institution to engage with the potential of resource lists that is the essential requisite of doing it well. Students need to find the experience of resource lists rewarding, the materials easy to access; and as few barriers as possible between their VLE, resource lists and resource delivery systems. Academics need to see return on the investment in resource list work; and recognise of a virtuous circle of engagement and improved student satisfaction. In ever more budget-conscious times, academic libraries need to demonstrate that they are acquiring and delivering the resources required to support teaching and learning at their institution. 
The success of a RLMS project within an HE institution will ultimately depend upon the extent to which resource list activity is reflected in the teaching, learning and resourcing strategies and policies of the university; the degree to which resource list adoption is ubiquitous standard practice for taught courses; and the ability of the library services to optimise the processes which underpin, provision and validate lists and support academics in the resource selection aspects of list authoring.

But these objectives are themselves the means to the ultimate goal: that a resource list 'contract' between the library service and academics provides students with the guided awareness of resource list materials and effective access to those materials; and that student satisfaction levels around 'direct reading' are improved. The impact that the launch of a comprehensive RLMS service can have on the responsibilities, priorities and workflows of team across an HE library service should not be under-estimated. There can be no question, however, that the introduction of a next generation resource list solution can enable a library service to support academics in transforming the quality, efficiency and responsiveness of the resource list environment on which outcome-focused, feeconscious students will increasingly come to rely in the years ahead.

\section{References}

Atkinson, S. (2010), "Reading lists - pitching it right!", SCONUL Focus, No. 50, pp. 75-79.

Boyle, F. (2004), "The JIBS Workshop on Resource/Reading List Software - The Reality", Ariadne, No. 41.

Brewerton, G. \& Knight, J. (2003), "From local project to open source: a brief history of the Loughborough Online Reading List System (LORLS)", VINE, Vol. 33, No. 4, pp. 189-195.

Chad, K. (2010), "A perspective on resource list management", Library \& Information Update, Vol. 9, No. 5, pp. 39-41. 
Chad, K. (2012), "Reading Resource Lists", Sconul Higher Education Library Technology (HELibtech) wiki, available at:

http://helibtech.com/Reading_Resource+lists (accessed 10 April 2013).

Chelin, J., McEachran, M. \& Williams, E. (2005), "Five hundred into 4 won't go how to solve the problem of reading list expectations", SCONUL Focus, No. 36, pp. 49-51.

Clarke, C. (2009), "A Resource List Management Tool for Undergraduate Students Based on Linked Open Data Principles", Lecture Notes in Computer Science, Vol. 5554, 697-707.

Cross, R., (2011a), "Running a Resource List Service: Opportunities and Challenges for Students, Academics and Librarians", Talis Aspire Open Day, 17 November, available at: http://www.youtube.com/watch?v=nRMpbJV-RNo (accessed 9 April 2013).

Cross, R., (2012), "Resource Lists and e-Resources: Discovery and Management Challenges", United Kingdom Serials Group (UKSG) Conference 2012, 27-28 March, available at http://www.slideshare.net/UKSG/talis-aspire-ntu-26032012 (accessed 15 April 2013).

Knight, J., Cooper, J., Brewerton, G. (2012). "Redeveloping the Loughborough Online Reading List System", Ariadne, No 69, available at: http://www.ariadne.ac.uk/issue69/knight-et-al (accessed 12 April 2013).

Martin, L. \& Stokes, P. (2006), "Reading lists under the spotlight: Cinderella or superstar?", SCONUL Focus, No. 37, pp. 33-36.

McDowell, L. (2002), "Electronic information resources in undergraduate education: an exploratory study of opportunities for student learning and independence", British Journal of Educational Technology, Vol. 33, No. 3, pp. 255-266. 
Morgan, R. (2007), "The online reading list project using Talis List at the University of Glamorgan", Program: electronic library and information systems, Vol. 41, No. 3, pp. 262-275.

Pitkin, K. (2011), "Supporting Developer Success: The List8D Story", DevCSI blog, 18 May, available at: http://devcsi.ukoln.ac.uk/2011/05/18/supportingdeveloper-success-list8d/ (accessed 5 March 2013).

Sotillo, J. (2012), "List8D: open source reading list system", University of Kent web site, available at: http://www.kent.ac.uk/is/projects/list8d/index.html (accessed 12 March 2013).

Stainthorp, P. (2011), "Reading list management software - what are the options?", available at: http://www.slideshare.net/pstainthorp/reading-listmanagement-software-what-are-the-options (accessed 4 January 2013).

Rieger, O.Y., Horne, A.K. \& Revels, I. (2004), "Linking Course Web Sites to Library Collections and Services", Journal of Academic Librarianship, Vol. 30, No. 3, pp. 205-211.

Secker, J. (2005), "DELIVERing library resources to the virtual learning environment", Program: Electronic Library \& Information Systems, Vol. 39, No. 1, pp. 39-49.

Sherwood, K. \& Lovecy, I. (1997), "The provision of recommended reading in an academic library", Library Management, Vol. 18, pp. 356-360.

Stopforth, C. (1994), "Provision of Reading List Texts in an Academic Library", Library Management, Vol. 15, No. 3, pp. 14-20.

Telstar. (2010), "Integrating References and Citations into Learning Environments", Telstar blog, available at: http://www.open.ac.uk/blogs/telstar/ (accessed 4 January 2013). 
Young, Hannah. (2012), "Reading Lists and Referencing: RefWorks Integration in Moodle", RefWorks User Group UK meeting, 20 September, available at: http://goo.gl/ol67H (accessed 7 December 2012).

\section{Further reading}

Bartlett, S. (2010), "Resource List management - a system-based approach", Library \& Information Update, Vol. 9, No. 5, pp. 42-43.

Manchester Metropolitan University. (2011). "Working with partners: Talis Aspire and Equella", JISC W2C Project Blog, available at:

http://Irt.mmu.ac.uk/w2c/2011/06/15/working-with-partners-talis-aspire-andequella/ (accessed 10 April 2013).

Talis. (2010), "Case Study: Nottingham Trent University and Talis Aspire Engaging academic champions to transform resource list practices", available at: http://www.talisaspire.com/newsletter/september-2010/ (accessed 4 January 2013).

Talis, (2011a), "Transforming reading lists... and student satisfaction ratings", UNImag, No. 3, pp. 12-13, available at: http://www.uni-mag.co.uk/Uni-issues2011.html (accessed 4 January 2013).

Talis. (2011b), "Undergraduates at Nottingham Trent University Discuss Talis Aspire Campus Edition", available at: http://youtu.be/BCvyMV8vikw (accessed 5 December 2012).

Talis. (2011c), "Dr Gary Motteram talks about Talis Aspire Campus Edition", available at: http://youtu.be/ucsIX6wMcqo (accessed 5 December 2012).

\section{Author}

Dr Richard Cross leads the Resource Discovery and Innovation Team within Libraries and Learning Resources at Nottingham Trent University, and was the technical lead on LLR's implementation of Talis Aspire. He earlier led the technical implementation of the university's institutional repository, and has more recently implemented the library's new discovery service. Between 2009 
and 2012, he was Chair of the Ex Libris User Group (United Kingdom and Ireland).

\section{Notes}

1 University of Aberystwyth (Readings Management System), http://arms.mis.aber.ac.uk/; University of Huddersfield (MyReading), http://library.hud.ac.uk/myreading/; University of Leeds (Reading Lists), http://lib5.leeds.ac.uk/rlists/; University of York (EARL - Easy Access to Resource Lists), http://www.york.ac.uk/univ/org/vle/vle/search/guides-search.cfm?keywords=EARL; University of Worcester (Reading Lists), https://secure.worc.ac.uk/cgibin/library/readinglists/list.pl

2 Talis Education (Talis Aspire), http://www.talisaspire.com; PTFS Europe (Rebus:list), http://www.ptfs-europe.com/products/rebus/rebuslist/; UNILIBRI (UNILIBRI), http://unilibri.com/site/; Student Reading Lists (Student Reading Lists), http://www.studentreadinglists.com ${ }^{3}$ This is premised on providers publishing the relevant metadata in the head HTML code of their pages, something requested by Google Scholar in its specification for effective indexing: http://scholar.google.com/intl/en/scholar/inclusion.html 